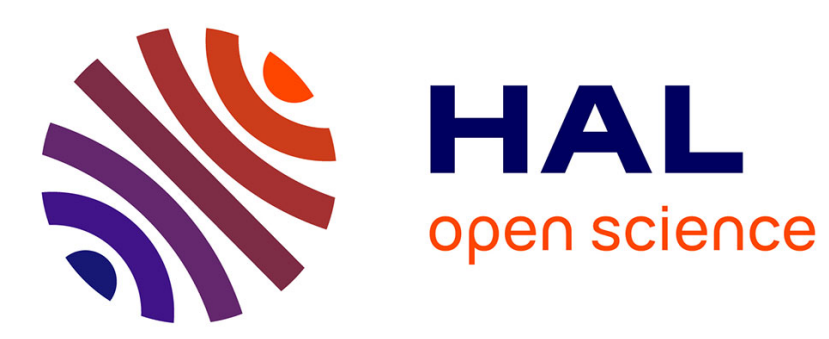

\title{
Population pharmacokinetic analysis of free and bound aflibercept in patients with advanced solid tumors.
}

Hoai-Thu Thai, Christine Veyrat-Follet, France Mentré, Emmanuelle Comets

\section{To cite this version:}

Hoai-Thu Thai, Christine Veyrat-Follet, France Mentré, Emmanuelle Comets. Population pharmacokinetic analysis of free and bound aflibercept in patients with advanced solid tumors.. Cancer Chemotherapy and Pharmacology, 2013, 72 (1), pp.167-80. 10.1007/s00280-013-2182-1 . inserm00881821

\section{HAL Id: inserm-00881821 https://www.hal.inserm.fr/inserm-00881821}

Submitted on 6 May 2014

HAL is a multi-disciplinary open access archive for the deposit and dissemination of scientific research documents, whether they are published or not. The documents may come from teaching and research institutions in France or abroad, or from public or private research centers.
L'archive ouverte pluridisciplinaire $\mathbf{H A L}$, est destinée au dépôt et à la diffusion de documents scientifiques de niveau recherche, publiés ou non, émanant des établissements d'enseignement et de recherche français ou étrangers, des laboratoires publics ou privés. 


\section{Population pharmacokinetic analysis of free and bound aflibercept in patients with advanced solid tumors}

Hoai-Thu Thai ${ }^{1,2}$, Christine Veyrat-Follet ${ }^{1}$, France Mentré $^{2}$, Emmanuelle Comets ${ }^{2}$

${ }^{1}$ Drug Disposition Department, Sanofi, Paris, France

2 INSERM, UMR 738, F-75018 Paris, France; Univ Paris Diderot, Sorbonne Paris Cité, UMR 738, F-75018 Paris, France

Correspondance:

Hoai-Thu Thai

Sanofi R\&D

Disposition Safety \& Animal Research

1, avenue Pierre Brossolette

91380 Chilly-Mazarin

France

Tel: + 33160496512

Fax: +33160497161

Email: $\underline{\text { hoai-thu.thai@sanofi.com }}$

Keywords: Population pharmacokinetics, target-mediated drug disposition, aflibercept, VEGF, covariate effect, dosing schedule

Word count: 5100

Number of tables: 4

Number of figures: 6 


\begin{abstract}
Objective Aflibercept (Zaltrap $\left.{ }^{\circledR}\right)$ is a novel anti-angiogenic agent that binds to vascular endothelial growth factor (VEGF) and inhibits VEGF-dependent tumor growth. We aimed to characterize the population pharmacokinetics (PK) of free and bound aflibercept in patients with solid tumors, to examine the influence of covariates on their PK and to evaluate the proposed dosing regimens by simulation.
\end{abstract}

Methods Data from 9 clinical trials with 1506 cancer patients receiving aflibercept $(2-9 \mathrm{mg} / \mathrm{kg}$ every 2 or 3 weeks; 1 hour IV infusion) as a monotherapy or in combination with various chemotherapies were included. Free and bound aflibercept concentrations were analyzed using a nonlinear mixed-effects modeling approach with MONOLIX 4.1.2.

Results An approximation of a target mediated-drug disposition model with irreversible binding of free aflibercept to VEGF adequately described the PK of free and bound aflibercept. The typical estimated clearances for free $\left(C L_{f}\right)$ and bound aflibercept $\left(C L_{b}\right)$ were 0.88 and $0.19 \mathrm{~L} /$ day, respectively. The volumes of distribution for free $\left(V_{p}\right)$ and bound $\left(V_{b}\right)$ aflibercept were similar $(\sim 4 \mathrm{~L}) . C L_{f}$ and $V_{p}$ increased with body weight and were lower in women. Patients with low albumin (ALB) or high alkaline phosphatase (ALK) had faster $C L_{f}$ compared to a typical patient. Pancreatic cancer may be associated with changes in binding of aflibercept to VEGF. Simulations of different dosing regimens showed that adequate saturation of circulating VEGF was achieved with a dose of $4 \mathrm{mg} / \mathrm{kg}$ every 2 weeks.

Conclusions Aflibercept kinetics was most affected by gender, body weight, ALB, ALK and pancreatic cancer. Simulations supported the rationale for the recommended dose of $4 \mathrm{mg} / \mathrm{kg}$ every 2 weeks for aflibercept. 


\section{Introduction}

Malignant tumors are dependent on angiogenesis to maintain a source of nutrition and oxygen supporting their growth and metastasis [1]. Vascular endothelial growth factor (VEGF) is a homodimeric protein that activates two high-affinity receptors on the vascular endothelium (VEGFR1 and VEGFR2), promoting the formation of blood vessels that are required for normal and neoplastic tissue growth. VEGF has become a major target for anti-angiogenic therapy in managing cancers because its overexpression in several tumor types is associated with increased tumor vascularity, proliferation, progression, invasion, metastasis, and poor prognosis [2-4]. Preclinical studies have shown that inhibition of VEGF results in tumor growth inhibition in several human tumor xenografts in the nude mouse model, including colorectal cell lines [5].

Aflibercept (known as ziv-aflibercept in the United States; Sanofi, Paris, France, and Regeneron Pharmaceuticals, Tarrytown, NY) is a novel antiangiogenic agent [6]. It is a recombinant protein consisting of human VEGF receptor extracellular domains (domain 2 from VEGFR1 and domain 3 from VEGFR2) fused to the Fc portion of human immunoglobulin G1 (IgG1). Aflibercept binds to all isoforms of VEGF-A, VEGF-B and to placental growth factor (PIGF) [7]. It interferes with the biological actions of VEGF by forming a complex with VEGF in the blood stream and extravascular space and preventing it from interacting with its receptors on endothelial cells. The affinity of aflibercept for VEGF-A (Kd in vitro $=0.5 \mathrm{pM})$ is higher than that of anti-VEGF monoclonal antibodies, such as bevacizumab $(\mathrm{Kd}$ in vitro $=500 \mathrm{pM})[8,9]$.

Preclinical studies in mice have demonstrated the effects of aflibercept on capillary regression, narrowing of vessels, blood flow cessation as well as endothelial cell apoptosis [10]. Inhibition of tumor growth and tumor angiogenesis, inhibition of metastases and improved survival have been observed with aflibercept in tumor xenografts for various cancers [6,11,12]. Phase I doseescalation studies, Phase II and Phase III trials have explored the antitumor activity of aflibercept as a single agent or in combination with a number of chemotherapy agents/regimens, including in patients with non-small cell lung, ovarian, pancreatic and colorectal cancers [6,13-16]. Recently, aflibercept at $4 \mathrm{mg} / \mathrm{kg}$ every 2 weeks plus FOLFIRI (combination of 5-fluorouracil, leucovorin and irinotecan) has been demonstrated to improve overall survival, progression-free survival and response rate in patients with metastatic colorectal cancer [17-19]. 
During clinical development, data is accrued from different sources, such as phase I trials in healthy subjects and phase I to III trials in cancer patients. Modelling pharmacokinetic (PK) data allows us to integrate data from different clinical trials to update our knowledge about aflibercept and support drug development strategy. Following this approach, a population PK study was initiated with the aim of characterising the PK of aflibercept and quantifying parameter changes in different populations.

Previously, we reported the results of a population PK analysis of free and VEGF-bound aflibercept in 56 healthy subjects receiving single intravenous (i.v.) doses of 1 to $4 \mathrm{mg} / \mathrm{kg}$ recruited in two phase I clinical studies [20]. An approximation of a target mediated-drug disposition (TMDD) model with Michaelis-Menten (MM) type binding of free aflibercept to VEGF in the peripheral compartment was used to describe the PK profile of both free and bound aflibercept. This model adequately characterized the nonlinear binding of aflibercept to VEGF in this healthy subject population.

The objectives of this analysis were (i) to characterize the population PK of free and bound aflibercept in cancer patients by extending the model developed in healthy subjects; (ii) to investigate covariates that could influence their PK and (iii) to evaluate various dosing regimens by simulation.

\section{Methods}

Patient population and study design

A total of 9 clinical trials of aflibercept from Phase I to Phase III in 1506 patients with advanced solid tumors were included in the population analysis. Aflibercept was used as a single agent in 4 trials and in combination with cytotoxic chemotherapy regimens in 5 trials. A summary of clinical trials included in the analysis is given in Table 1. Phase I trials were conducted in patients with various types of solid tumors while Phase II and Phase III trials were conducted in patients with ovarian, pancreatic, lung and colorectal cancer. In these studies, aflibercept was administered as a 1 hour i.v. infusion at dose levels ranging from 2 to $7 \mathrm{mg} / \mathrm{kg}$ every 2 or 3 weeks and up to $9 \mathrm{mg} / \mathrm{kg}$ in every 3 weeks schedule only. Dose adjustments and/or cycle delays were 
permitted in case of toxicity. An intensive PK sampling scheme was implemented in Phase I studies as presented in Table 1. For Phase II and Phase III trials, PK samples were collected predose and at the end of aflibercept infusion on Day 1 (Cycle 1), then every odd cycle before treatment administration and at approximately 30 and 90 days after the last aflibercept treatment. All study protocols were in accordance with recommendations of the 18th World Health Congress (Helsinki, 1964) and complied with the laws and regulations, as well as any applicable guidelines, of the countries where the studies were conducted. All patients gave written informed consent.

\section{Assay method}

For all clinical trials, free aflibercept and bound aflibercept (VEGF:aflibercept complex) plasma concentrations were measured using enzyme-linked immunosorbent assay (ELISA) method. The anti-drug-antibodies (ADA) were also detected by a titer-based, bridging immunoassay to evaluate the potential effect of immunogenicity on the PK of aflibercept. Blood samples were collected in tubes (containing $1 \mathrm{~mL}$ of citrate buffer, sodium citrate, and $4.2 \mathrm{mg}$ of citric acid) and were centrifuged at $2000 \mathrm{~g}$ for 15 minutes at room temperature. Plasma was stored at $-80^{\circ} \mathrm{C}$ until analyzed.

In the assay of free aflibercept, human VEGF165 initially adsorbed to the surface of a polystyrene solid support was used to capture free aflibercept in the samples and then bound to a mouse antihuman specific VEGFR-1 monoclonal antibody. After that, the immobilized murine monoclonal complex was bound to a goat antimouse IgG antibody conjugated to Horseradish Peroxidase for detection. The limit of quantification (LOQ) for free aflibercept in plasma was initially 31.3 $\mathrm{ng} / \mathrm{mL}$ (for TED6115/TED6116), and then $15.6 \mathrm{ng} / \mathrm{mL}$ (for subsequent studies).

The assay of bound aflibercept was similar to that of free aflibercept, except for the use of the anti-human VEGF165 antibody instead of human VEGF165 a as the capture reagent in the coated plate. The LOQ for bound aflibercept in plasma was $43.9 \mathrm{ng} / \mathrm{mL}$.

Since bound aflibercept contains one molecule of endogenous VEGF and one molecule of aflibercept, bound aflibercept concentrations were expressed as free aflibercept equivalents for 
PK analyses using 0.717 , the ratio of molecular weights between free and bound aflibercept. The units of free and bound aflibercept concentrations were $\mu \mathrm{g} / \mathrm{mL}$ and $\mu \mathrm{g} . \mathrm{eq} / \mathrm{mL}$, respectively.

Population pharmacokinetic analysis

The population PK analysis was performed using a nonlinear mixed-effects modeling approach with MONOLIX 4.1.2 [21] implementing the SAEM algorithm [22]. The model control files were written using MLXTRAN script. Graphical analyses for model evaluation were performed with R 2.14.1.

\section{Structural model}

The previous population PK analysis of free and bound aflibercept in healthy subjects demonstrated that the irreversible MM (IB-MM) approximation of TMDD model was the best PK model for aflibercept. This model is shown in Figure 1 and includes 2 compartments for free aflibercept, 1 compartment for bound aflibercept and irreversible MM type binding of free aflibercept to VEGF in the peripheral compartment [20]. In addition, the dissociation rate constant $\left(k_{\text {off }}\right)$ which gives back free aflibercept and free VEGF was assumed to be negligible and is not represented on the Figure 1. The same model was applied to patient data.

In this model, the concentration of free aflibercept in central compartment $\left(C_{p}\right)$, in tissue compartment $\left(C_{t}\right)$ and the concentration of bound aflibercept $\left(C_{b}\right)$ are described by the following system of differential equations:

$$
\begin{aligned}
& \frac{d C_{p}}{d t}=\frac{R_{\mathrm{inf}}}{V_{p}}-\left(k_{e l}+k_{p t}\right) \cdot C_{p}+k_{t p} \cdot \frac{C_{t} \cdot V_{t}}{V_{p}} \\
& \frac{d C_{t}}{d t}=k_{p t} \cdot \frac{C_{p} \cdot V_{p}}{V_{t}}-k_{t p} \cdot C_{t}-\frac{1}{V_{t}} \cdot \frac{V_{\max } \cdot C_{t}}{K_{m}+C_{t}} \\
& \frac{d C_{b}}{d t}=\frac{1}{V_{b}} \cdot \frac{V_{\max } \cdot C_{t}}{K_{m}+C_{t}}-k_{\mathrm{int}} \cdot C_{b}
\end{aligned}
$$

in which $R_{\text {inf }}$ is the infusion rate, $k_{e l}\left(\mathrm{day}^{-1}\right)$ is the first order elimination rate constant of free aflibercept from the central compartment, $k_{t p}$ and $k_{p t}\left(\right.$ day $\left.^{-1}\right)$ are the first order rate constants between the central and the peripheral compartment, $k_{\text {int }}\left(\right.$ day $\left.^{-1}\right)$ is the first order rate constant of bound aflibercept internalization, $V_{p}(\mathrm{~L})$ is the central volume of distribution of free aflibercept, 
$V_{t}(\mathrm{~L})$ is the peripheral volume of distribution of free aflibercept, $V_{b}(\mathrm{~L})$ is the volume of distribution of bound aflibercept, $V_{\max }(\mathrm{mg} /$ day $)$ is the maximum binding capacity, $K_{m}(\mu \mathrm{g} / \mathrm{mL})$ is the concentration of free aflibercept corresponding to half of maximum binding capacity.

The clearances of free and bound aflibercept $\left(C L_{f}\right.$ and $\left.C L_{b}\right)$ and the intercompartmental clearance of free aflibercept $(Q)$ between the central and the peripheral compartments are derived from the micro-constant as follows:

$$
\begin{gathered}
C L_{f}=k_{e l} \cdot V_{p} \\
C L_{b}=k_{i n t} \cdot V_{b} \\
Q=k_{t p} \cdot V_{t}=k_{p t} \cdot V_{p}
\end{gathered}
$$

The parameters to be estimated in this model are: $C L_{f}, V_{p}, Q, V_{t}, C L_{b}, V_{b}, V_{\max }$, and $K_{m}$.

\section{Statistical model}

Denoting $f$ the function describing the PK structural model, the statistical model for observed concentration $C_{i j}$ of subjects $i$ for sampling time $t_{i j}$ is:

$$
C_{i j}=f\left(\theta_{i}, t_{i j}\right)+\varepsilon_{i j}
$$

where $\theta_{i}$ is the vector of parameters of subject $i$ and $\varepsilon_{i j}$ is the residual error.

The interindividual variability (IIV) on all parameters was modeled with an exponential model, implying a log-normal distribution for the parameters, e.g. for $C L$ :

$$
C L_{i}=C L e^{\eta_{C L, i}}
$$

where $\eta_{C L, i}$ denotes the random effect in subject $i, C L_{i}$ the individual clearance parameter and $C L$ the typical value of the population. Random effects were assumed to follow a normal distribution with zero mean and variance matrix $\Omega$, which was modeled as diagonal.

The residual variability was modeled using a combined additive and proportional model for both free and bound aflibercept. The residual errors for free aflibercept $\left(\varepsilon_{f r e e, i j}\right)$ and bound aflibercept $\left(\varepsilon_{\text {bound, } i j}\right)$ are assumed to be independent and normally distributed with mean zero and a heteroscedastic variance $\sigma_{\text {free, } i j}$ and $\sigma_{\text {bound }, i j}$ respectively, given by: 


$$
\begin{gathered}
\sigma_{\text {free }, i j}^{2}=\left(\sigma_{f a}+\sigma_{f p} f\left(\theta_{i}, t_{i j}\right)\right)^{2} \\
\sigma_{b o u n d, i j}^{2}=\left(\sigma_{b a}+\sigma_{b p} f\left(\theta_{i}, t_{i j}\right)\right)^{2}
\end{gathered}
$$

where $\sigma_{f a}$ and $\sigma_{f p}$ are respectively the additive and proportional coefficients of the residual error model of free aflibercept; $\sigma_{b a}$ and $\sigma_{b p}$ are respectively the additive and proportional coefficients of the residual error model of bound aflibercept.

Estimation of potential interoccasion variability (IOV) was not performed in this analysis because the data was very sparse, containing a trough concentration every two cycles for $90 \%$ of the patients.

The variability models were investigated. For parameters with an estimated low level of IIV, we tested whether IIV could be removed from the model. The likelihood ratio test was used to discriminate between variability models through the difference in log likelihood (-2LL), computed using important sampling [23]. A p-value of 0.05 was considered statistically significant.

\section{Covariate analysis}

The covariate analysis was performed after obtaining the base model and focused on the main parameters describing the PK of free and bound aflibercept and their binding to VEGF: $C L_{f}, V_{p}$, $V_{\max }, K_{m}$ and $C L_{b}$.

The following covariates were included in the analysis: patient demographics (age, gender, weight and ethnicity), laboratory measurements at baseline (albumin (ALB), serum alkaline phosphatase (ALK), total bilirubin (BIL), aspartate amino transferase (AST), alanine amino transferase (ALT), total protein (TP), and creatinine clearance (CLCR)) and concomitant chemotherapy (irinotecan/5-FU/LV in TCD6118, docetaxel in VITAL and TDC6120, gemcitabine in VANILLA and FOLFIRI in VELOUR).

In this work, the effect of study and the effect of cancer type were not tested as these were confounded with the effect of chemotherapy (see Table 1). The effect of baseline endogenous 
VEGF concentrations on PK aflibercept would have been interesting to investigate; however the large amount of missing values (62\% of patients) precluded this as a covariate in the modeling.

The parameter-covariate relationships were modeled multiplicatively as follows (e.g. for CL):

$$
C L_{i}=C L\left(\frac{\operatorname{COV}_{i}}{\operatorname{COV}_{\text {median }}}\right)^{\beta} e^{\eta_{C L, i}} \quad \text { for continuous covariates }
$$

where $\beta$ are the regression coefficient to be estimated, $C O V_{\text {median }}$ is the median value of covariates.

or

$$
C L_{i}=C L \cdot e^{\beta \cdot \operatorname{COV}_{i}} e^{\eta_{C L, i}} \quad \text { for dichotomous covariates } C O V_{i} \text { taking } 0 \text { or } 1 \text { values }
$$

The construction of the covariate model was performed with hypothesis testing using the Wald test [24] in two steps:

- Step 1: For covariate screening, each potential parameter-covariate relationship was included one by one in the base model and the parameters were estimated. The significance of a covariate effect was then assessed using the Wald test.

- Step 2: All the significant covariates were included in the base model. The final model was built using a backward stepwise procedure by removing the non-significant covariates one by one, starting from the full model and removing the effect having the largest non-significant p-value of the Wald test. This step was repeated until only significant covariates remain in the model.

A p-value of 0.05 was considered statistically significant in both steps.

\section{Model evaluation}

Internal evaluation of the model was based on goodness-of-fit (GOF) plots, including plots of observations versus individual and population predictions. Plots of normalized prediction distribution error (NPDE) [25,26] versus time since last dose (TimeL) were used to assess model predictive performance, based on the simulation of 1000 datasets. The NPDE plots with 95\% prediction intervals around the $10^{\text {th }}, 50^{\text {th }}$ and $90^{\text {th }}$ percentiles were generated using the package NPDE 2.0 for R [27]. We also computed the $\eta$-shrinkage for each parameter and $\varepsilon$-shrinkage separately for free and bound aflibercept data to quantify the amount of information in the 
individual data about the parameters [28]. Model evaluation was performed for both the base model and the final model.

\section{Model-based simulations}

In order to compare the time course of free and bound aflibercept concentrations after different dosing regimens $(2,4$ or $6 \mathrm{mg} / \mathrm{kg}$ q2 $\mathrm{wk}$ or $\mathrm{q} 3 \mathrm{wk})$, the estimates of the fixed and random effects obtained in the final model were used to simulate the steady-state PK profiles of free and VEGFbound aflibercept in 1000 virtual patients. To mimic the actual treated population, the covariates were obtained by resampling 1000 patients from the 1506 patients in the study and collecting the set of covariates characterising each patient. The median bound concentrations of different doses for every 2 and 3 weeks regimens were compared to evaluate the optimal dosing regimen for achieving VEGF blockade. The median, $5^{\text {th }}$ and $95^{\text {th }}$ percentiles of free and bound aflibercept concentrations versus time were plotted for the recommend dose ( $4 \mathrm{mg} / \mathrm{kg} \mathrm{q} 2 \mathrm{wk}$ ) to confirm the saturation of the binding of free aflibercept to VEGF during the treatment period.

\section{Results}

\section{Demographics}

The database for this population PK analysis consisted of 1506 patients including 151 patients from Phase I studies, 282 patients from Phase II studies and 1073 patients from Phase III studies. Patients found to be ADA positive were only found to have low titer levels and ADA positivity did not result in any observed impact on aflibercept PK (data not shown). As the result, all ADA positive patients (less than $5 \%$ of the analysis population) including those found to be ADA positive only at baseline were included in this analysis. The characteristics of these patients are shown in Table 2.

The majority of patients included in this analysis were Caucasians aged 65 years old and over and equally balanced between genders. Almost all the patients had normal renal function (CLCR: $>80$ $\mathrm{mL} / \mathrm{min}$ ) or mild renal dysfunction (CLCR: $50-80 \mathrm{~mL} / \mathrm{min}$ ). In this analysis, approximately one third of the patients had colorectal cancer, one third had lung cancer and the remaining third had other various solid tumors. Most patients received aflibercept in combination with chemotherapy. 
Approximately $90 \%$ of patients were recruited in phase II and III studies and had limited pharmacokinetic sampling with only one peak and multiple trough concentrations of free and bound aflibercept.

Population pharmacokinetic model building

Base model development was performed using a data set including 1506 patients with 7916 free aflibercept concentrations and 6977 bound aflibercept concentrations greater than LOQ. The below quantification limit (BQL) data for free aflibercept (5.7\%) and bound aflibercept (17.2\%) were omitted in this analysis. The concentrations of both free and bound aflibercept were measured for 1378 patients while only free aflibercept concentrations were available for 128 remaining patients.

The TMDD model with IB-MM approximation previously developed in healthy subjects provided an adequate fit to the PK data of both free and bound aflibercept in patients. The IIV on maximum binding capacity $\left(V_{\max }\right)$ was found to be small $(6 \%)$ and poorly estimated. Removing the variability for this parameter did not degrade the fit, with even a decrease of 5 points in $-2 \mathrm{LL}$ values, probably as a result of improved model stability and estimation of other parameters. A combined additive and proportional residual error was retained for both free and bound aflibercept. The parameter estimates of the base model are shown in Table 3. Both fixed and random effects were precisely estimated with relative standard errors (RSEs) of less than 22\%. The $\eta$-shrinkage was large for most parameters, reflecting the lack of information in the patients with sparse sampling, representing $90 \%$ of the subjects in the pooled dataset: $C L_{f}(37 \%), V_{p}$ (69\%), $Q$ (86\%), $V_{t}(64 \%), V_{b}(73 \%), K_{m}(95 \%), C L_{b}(48 \%)$. The $\varepsilon$-shrinkage was $23 \%$ for the data of free aflibercept and $19 \%$ for the data of bound aflibercept.

Seventeen potential covariates were evaluated for aflibercept by testing them on $C L_{f}, V_{p}, K_{m}$, and $C L_{b}$ in the base model. They were not tested on $V_{\max }$ as its IIV was set to zero. Based on the Wald test of the univariate analysis using modeling, the following covariates were found to have an influence on PK parameters and were considered for inclusion in the model: gender, age, weight, CLCR, ALB, ALK, AST, ALT and all the concomitant chemotherapies. Ethnicity appeared to have no significant effect on aflibercept PK. After removing non significant covariates one by 
one starting from the full model, the final model was achieved, with parameter estimates and the coefficients of all significant covariates presented in the Table 3.

The parameters in the final model were estimated with reasonable precision: RSEs $\leq 10 \%$ for PK parameters, RSEs $\leq 42 \%$ for random effects and RSEs $\leq 46 \%$ for the coefficients of the significant covariates. The PK parameter estimates of the final model were similar to those of the base model. In the final model, the typical estimated clearance for free aflibercept was about 4.6 times faster than that of bound aflibercept ( 0.88 and $0.19 \mathrm{~L} /$ day, respectively). The volumes of distribution for free aflibercept $\left(V_{p}\right)$ and bound aflibercept $\left(V_{b}\right)$ were similar $(\sim 4 \mathrm{~L})$. The maximum binding capacity was $0.82 \mathrm{mg} /$ day and the concentration of free aflibercept corresponding to half of maximum binding capacity in this patient data set was $1.92 \mu \mathrm{g} / \mathrm{mL}$.

The IIV on model parameters was moderate to high, ranging from $22.3 \%\left(C L_{b}\right)$ to $85.5 \%\left(C L_{f}\right)$. There was a small decrease in the estimates of the variabilities of all parameters, except $Q$ and $V_{t}$ when including covariates in the model. Residual variability was moderate for free aflibercept (proportional errors of $32.9 \%$ ) but low for bound aflibercept (proportional errors of $9.01 \%$ ).

The goodness-of-fit plots of the final model with covariates are shown in Figures 2 and 3. The plots of observations versus population and individual predictions (Figure 2) indicated that the model adequately described the observations despite an underprediction of high concentrations of free aflibercept. The plots of NPDE versus time since last dose (timeL) are presented in Figure 3 for the duration of the study (timeL $\leq 22$ weeks). Here, NPDE plots are more appropriate than VPC (visual predictive check) plots because of the heterogeneity in sample times and doses $[25,26]$. An inset is shown plotting only the data for 6 weeks after the last treatment (timeL $\leq 6$ weeks), which was the period of time where most of the observations were collected. The NPDE plots showed a symmetric distribution around zero for both free and bound aflibercept. The prediction bands indicated good model adequacy except for two issues. First, prediction intervals appear to be too large at time $\mathrm{L} \geq 14$ weeks; this could be an artifact due to the small number of measurements late after the last dose. Second, the variability at early times for bound aflibercept is underestimated; this could be a consequence of the BQL data not being included in the database. Individual plots for free and bound aflibercept are shown in Figure 4 for 4 subjects from 4 different studies. For most subjects, the model described reasonably well the observations for both free and bound aflibercept. 
Assessment of covariate effects

The magnitude of the effect of covariates on aflibercept PK parameters in the final model is shown in Table 4. Gender, body weight, ALB and ALK had the largest effects on $C L_{f} . C L_{f}$ increased $12 \%$ for patients with a WT of $99 \mathrm{~kg}$ compared to the value of a typical $70 \mathrm{~kg}$ male subject and was $14 \%$ smaller in women compared to men. A patient with low serum ALB (normalized ALB of 0.57 ) would be expected to have $14.06 \%$ faster $C L_{f}$ while patients with a high concentration of ALK (normalized ALK of 1.01) would have a $14.41 \%$ faster $C L_{f}$ compared to a patient with median values of ALB and ALK. Gender and body weight also had significant effects on $V_{p}$ with a $14.6 \%$ increase for a WT of $99 \mathrm{~kg}$ and a $19 \%$ decrease in women. Conversely, the covariate effects on $C L_{b}$ were very small with less than $10 \%$ changes in $C L_{b}$ compared to a typical subject, except for the effect of chemotherapy for irinotecan/5-FU/LV with a decrease of $12 \%$ of $C L_{b}$. The most important covariate associated with a change in the binding kinetics of aflibercept to VEGF, expressed by the irreversible binding constant $K_{m}$, was observed in patients with pancreatic cancer treated with gemcitabine in the study VANILLA. These patients had a $K_{m}$ increased by $82 \%$ compared to the typical patient receiving aflibercept as a monotherapy. A decrease of $20 \%$ in $K_{m}$ was also observed in women compared to typical men while an increase in $K_{m}$ was also observed in patients with high level of ALT or low level of AST compared to the typical patient. However, the high positive correlation between ALT and AST implies a small overall effect on $K_{m}$, with less than $10 \%$ of change compared to the typical value of 1.92. Combining all the covariate effects on $K_{m}$ explained $31.5 \%$ of the IIV in this parameter. For other parameters, the covariate effects explained very little the IIV on their parameters: $12.2 \%$ for $C L_{f}, 16.4 \%$ for $V_{p}$ and $5 \%$ for $C L_{b}$.

Simulation of various dosing regimens

The final PK model was used to simulate the concentration-time courses at steady-state of free and bound aflibercept for 1000 virtual patients receiving 8 doses of 2,4 or $6 \mathrm{mg} / \mathrm{kg}$ every 2 weeks or 6 doses of 2,4 or $6 \mathrm{mg} / \mathrm{kg}$ every 3 weeks. Figure 5 presents the predicted median profiles of bound aflibercept at steady-state for these different dosing regimens. Similar bound aflibercept levels were observed between $4 \mathrm{mg} / \mathrm{kg}$ and $6 \mathrm{mg} / \mathrm{kg}$ for q2wk regimen, indicating saturation of binding of aflibercept to circulating VEGF was reached at doses $\geq 4 \mathrm{mg} / \mathrm{kg}$. In addition, same bound aflibercept levels were shown between the $4 \mathrm{mg} / \mathrm{kg} \mathrm{q} 2 \mathrm{wk}$ regimen and the 
$6 \mathrm{mg} / \mathrm{kg}$ q3wk regimen, suggesting similar saturation of circulating VEGF for these two regimens. The predicted steady-state concentrations of free and bound aflibercept are presented in Figure 6. It illustrated that the free aflibercept concentrations remain greater than bound aflibercept concentrations throughout all the dosing intervals in most patients receiving $4 \mathrm{mg} / \mathrm{kg}$ q2wk. As aflibercept binds to VEGF with a 1:1 ratio, maintaining free drug concentrations above bound drug concentrations throughout the dosing intervals would maximize binding of aflibercept to endogenous VEGF.

\section{Discussion}

In this study, we present a population PK analysis of free and bound aflibercept in 1506 patients with advanced solid tumors from 9 clinical trials. Aflibercept was administered intravenously every two weeks as a single agent, every two or three weeks in combination with various chemotherapy drugs at dose levels ranging from 2 to $7 \mathrm{mg} / \mathrm{kg}$ and up to $9 \mathrm{mg} / \mathrm{kg}$ in the every 3 weeks schedule only. The influence of covariate effects on aflibercept pharmacokinetics was studied and quantified.

Based on the mechanism of action, aflibercept exhibits a target-mediated drug disposition (TMDD) as the binding of the drug to the target influence the pharmacokinetics of the drug. A general TMDD model describes the elimination pathway of drug plasma concentrations as the combination of first-order elimination from the central compartment and specific target binding clearance followed by internalization of drug-target complex [29]. The binding of the drug to the target can occur predominantly in the central or the peripheral compartment [30]. The full TMDD model is however complex and generally overparameterised. As a result, several approximations of TMDD model have been proposed: quasi equilibrium (QE), quasi steady state (QSS) and Michaelis-Menten (MM) [31-33]. The QE approximation is based on the assumption that the drug-target binding is much faster than all other system processes. The QSS approximation assumes the drug-target complex concentration changes more slowly than the binding and internalization process. The MM approximation describes the system when the target concentration is small relative to the free drug concentration and the dosing regimens result in the target being fully saturated [32]. Recently, a new derivation of MM approximation of TMDD model, the irreversible binding MM (IB-MM) model, can be used when the dissociation rate constant is negligible [33]. This is the model we used previously in healthy subjects. In this 
model, the MM parameters $\left(V_{\max }, K_{m}\right)$ are related to TMDD model parameters: $V_{\max }=k_{s y n} . V_{R}$ and $K_{m}=K_{I B}=k_{\mathrm{deg}} / k_{o n}$, where $V_{R}$ is the volume of distribution of target and $K_{I B}, k_{s y n}, k_{\mathrm{deg}}$ are the irreversible binding constant, target production rate and target degradation rate, respectively [6].

In the present study, the same structural model was applied successfully in patients, suggesting the similarity in binding kinetics of aflibercept to VEGF in cancer patients and healthy subjects: irreversible binding occurring dominantly in the peripheral compartment (extravascular space). This is in agreement with large quantities of VEGF in tumors and skeletal muscle [34]. Compared to healthy subjects, the population estimates for the clearance of free aflibercept in typical $70 \mathrm{~kg}$ male cancer patients were the same $(0.88 \mathrm{~L} / \mathrm{hr})$ while the clearance of bound aflibercept was slightly faster ( 0.14 vs $0.19 \mathrm{~L} /$ day). Similar values of $V_{p}$ and $V_{b}$ (around $4 \mathrm{~L}$ ) were also observed, indicating a low level of tissue diffusion of aflibercept in both healthy subjects and patients. In this analysis, the volume of distribution $V_{b}$ was correctly estimated with similar value to $V_{p}$ while it had to be fixed to the value of $V_{p}$ in the analysis of healthy subjects due to identifiability issues. The MM parameters $\left(V_{\max }\right.$ and $\left.K_{m}\right)$, reflecting the binding of aflibercept to VEGF, were however lower in cancer patients than in healthy subjects $(0.82 \mathrm{mg} /$ day and 1.92 $\mu \mathrm{g} / \mathrm{mL}$ vs $0.99 \mathrm{mg} / \mathrm{day}$ and $2.91 \mu \mathrm{g} / \mathrm{mL}$, respectively). These findings were not expected. $K_{m}$ should be similar for these two populations and $V_{\max }$ should be higher in cancer patients because of the faster secretion rate of VEGF and larger volume of distribution of VEGF in tumor tissue than in healthy tissue [35]. The comparison of binding kinetics between healthy subjects and patients is somewhat difficult because the designs and the studied doses were quite different in these two populations. The binding parameter estimates obtained in the previous study for healthy subjects may be impacted by the lower doses (e.g $1 \mathrm{mg} / \mathrm{kg}$ ) given as single administration, and non available data of bound aflibercept at late time points compared to those measured in patients. It may also explain slightly faster clearance estimation for bound aflibercept. However, PK findings in healthy volunteers addressed many aspects of general clinical pharmacology and helped us to well identify the model structure thanks to homogenous data before moving to heterogeneous data pooled from different clinical studies, containing a lot of sparse data.

The covariate screening was performed using the modeling approach rather than using the Empirical Bayes Estimates of individual parameters because of the large shrinkage of parameters 
in the base model. A backward stepwise elimination procedure was used to build the final model using the Wald test. Among all covariates tested, gender had the largest effects on both $C L_{f}$ and $V_{p}$ while gemcitabine had the largest effect on $K_{m}$. Body weight also had important effect on $C L_{f}$ and $V_{p}$. The impact of the correlation between body weight and gender was found to be less significant due to the large varibilities in body weight observed in men and women. Moreover, the inclusion of both gender and body weight improved the model fit.

Patients with low serum albumin concentrations or high concentrations of alkaline phosphatase had approximately $14 \%$ faster $C L_{f}$ and $32 \%$ lower exposure to free aflibercept compared to a typical patient with normal ALB or ALK. These effects were also found for total bevacizumab [36]. Low albumin and high alkaline phosphatase are generally indicative of disease severity and tumor burden [36] and may be the underlying cause of this association. In addition, an effect of albumin on clearance has been shown in the PK analysis of the monoclonal antibody, infliximab in patients with ulcerative colitis [37].

A finding of note in this study is the important increase (82\%) of the irreversible binding constant $\left(K_{m}\right.$ or $\left.K_{I B}\right)$ found in pancreatic cancer patients treated with gemcitabine in the VANILLA study. However, it may be not be reasonable to assume that the affinity of aflibercept for VEFG varies from one cancer to another, and this increase may in fact reflect differences in $V_{\max }$. Indeed, in the first steps of modeling, variability was included in the model for both $V_{\max }$ and $K_{m}$, but the former was removed because the model was not stable enough and the variability was very small and poorly estimated. However, since the correlation between $V_{\max }$ and $K_{m}$ was very high (0.9), the apparent elevated value of $K_{m}$ may indicate a decrease in maximal binding capacity $\left(V_{\max }\right)$ or in production rate of VEGF $\left(k_{s y n}\right)$. This would be related to the poorly vascularised nature of pancreatic tumors [38]. Unlike many other solid tumor types where the formation of new blood vessels (angiogenesis) promotes tumor growth by ensuring proper blood supply to the tumor, delivering nutrients and oxygen; pancreatic tumors do not need to create new blood vessels. They are able to survive with poor vasculature and under very low oxygen conditions, which makes drug delivery to pancreatic tumors especially difficult [39]. This has been suggested to be the reason why pancreatic cancer patients often have poor response to chemotherapy, even in combination with anti-VEGF agents administered intravenously [39,40]. 
Although several covariates were found significant in the final model, their contribution to aflibercept pharmacokinetics was mostly small with potential changes less than $20 \%$ (ranging from 3 to $18 \%$ ) in $C L_{f}, C L_{b}$ and $V_{p}$. As a result, the impact on VEGF inhibition would be minimal from a pharmacodynamic point of view. Conversely, the change in the maximal binding capacity of aflibercept to VEGF in patients with pancreatic cancer was much more important and may have contributed to the outcome of the VANILLA study in pancreatic cancer with the $4 \mathrm{mg} / \mathrm{kg}$ every 2 weeks regimen for aflibercept.

The final PK model was used to simulate the concentration-time courses of free and VEGFbound aflibercept for 1000 virtual patients for different doses of aflibercept. Assuming the level of VEGF-bound aflibercept can be used as a marker of VEGF blockade [41], this simulation allowed us to confirm the choice of the recommended dose of $4 \mathrm{mg} / \mathrm{kg}$ every 2 weeks which is sufficient to saturate circulating VEGF in most patients. The developed model can be used to simulate and predict the concentration-time profiles of free and bound aflibercept in a patient population of interest, for example obese patients and patients with low albumin, with new dosing regimens. From a clinical perspective, it would be interesting to model the relationship between concentrations and a direct marker of aflibercept efficacy, such as the tumor sizes.

In summary, the present model adequately described the pharmacokinetics of free and bound aflibercept in cancer patients. The most important covariates affecting aflibercept kinetics were gender, body weight, ALB, ALK and pancreatic cancer. This model supported the rationale for the recommended dose of $4 \mathrm{mg} / \mathrm{kg}$ every 2 weeks for aflibercept in colorectal cancer.

\section{Conflict of Interests}

During this work, Hoai-Thu Thai was a PhD student with a research grant funded by Sanofi and UMR 738 INSERM- University Paris Diderot (head Professor France Mentré) had a research grant from Sanofi. Christine Veyrat-Follet is employee of Sanofi.

\section{References}

1. Folkman J (1997) Addressing tumor blood vessels. Nat Biotechnol 15 (6):510

2. Takahashi Y, Kitadai Y, Bucana CD, Cleary KR, Ellis LM (1995) Expression of vascular endothelial growth factor and its receptor, KDR, correlates with vascularity, metastasis, and proliferation of human colon cancer. Cancer Res 55 (18):3964-3968 
3. Takebayashi Y, Aklyama S, Yamada K, Akiba S, Aikou T (1996) Angiogenesis as an unfavorable prognostic factor in human colorectal carcinoma. Cancer 78 (2):226-231

4. Radinsky R, Ellis LM (1996) Molecular determinants in the biology of liver metastasis. Surg Oncol Clin North Am 5 (2):215-229

5. Ferrara N, Davis-Smyth T (1997) The biology of vascular endothelial growth factor. Endocr Rev 18 (1):4-25

6. Gaya A, Tse V (2012) A preclinical and clinical review of aflibercept for the management of cancer. Cancer Treat Rev 38 (5):484-493

7. Sternberg CN (2008) Systemic chemotherapy and new experimental approaches in the treatment of metastatic prostate cancer. Ann Oncol 19 Suppl 7:vii91-95

8. Chu QS (2009) Aflibercept (AVE0005): an alternative strategy for inhibiting tumour angiogenesis by vascular endothelial growth factors. Exp Opin Biol Ther 9 (2):263-271

9. Lockhart AC, Rothenberg ML, Dupont J, Cooper W, Chevalier P, Sternas L, Buzenet G, Koehler E, Sosman JA, Schwartz LH, Gultekin DH, Koutcher JA, Donnelly EF, Andal R, Dancy I, Spriggs DR, Tew WP (2009) Phase I study of intravenous vascular endothelial growth factor trap, aflibercept, in patients with advanced solid tumors. J Clin Oncol 28 (2):207-214

10. Baffert F, Le T, Sennino B, Thurston G, Kuo CJ, Hu-Lowe D, McDonald DM (2006) Cellular changes in normal blood capillaries undergoing regression after inhibition of VEGF signaling. Am J Physiol 290 (2):H547-559

11. Holash J, Davis S, Papadopoulos N, Croll SD, Ho L, Russell M, Boland P, Leidich R, Hylton D, Burova E, Ioffe E, Huang T, Radziejewski C, Bailey K, Fandl JP, Daly T, Wiegand SJ, Yancopoulos GD, Rudge JS (2002) VEGF-Trap: a VEGF blocker with potent antitumor effects. Proc Nat Acad Sci USA 99 (17):11393-11398

12. Eichten A, Adler A, Cooper B, Griffith J, Wei Y, Yancopoulos G, Lin H, Thurston G (2012) Rapid decrease in tumor perfusion following VEGF blockade predicts long-term tumor growth inhibition in preclinical tumor models. Angiogenesis 16(2):429-441

13. Freyer G, Isambert N, You B, Zanetta S, Falandry C, Favier L, Trillet-Lenoir V, Assadourian S, Soussan-Lazard K, Ziti-Ljajic S, Fumoleau P (2012) Phase I dose-escalation study of aflibercept in combination with docetaxel and cisplatin in patients with advanced solid tumours. British J Cancer 107(4):598-603

14. Coleman RL, Duska LR, Ramirez PT, Heymach JV, Kamat AA, Modesitt SC, Schmeler KM, Iyer RB, Garcia ME, Miller DL, Jackson EF, Ng CS, Kundra V, Jaffe R, Sood AK (2011) Phase 1-2 study of docetaxel plus aflibercept in patients with recurrent ovarian, primary peritoneal, or fallopian tube cancer. Lancet Oncol 12 (12):1109-1117

15. Colombo N, Mangili G, Mammoliti S, Kalling M, Tholander B, Sternas L, Buzenet G, Chamberlain D (2012) A phase II study of aflibercept in patients with advanced epithelial ovarian cancer and symptomatic malignant ascites. Gynecol Oncol 125 (1):42-47

16. Ramlau R, Gorbunova V, Ciuleanu TE, Novello S, Ozguroglu M, Goksel T, Baldotto C, Bennouna J, Shepherd FA, Le-Guennec S, Rey A, Miller V, Thatcher N, Scagliotti G (2012) Aflibercept and docetaxel versus docetaxel alone after platinum failure in patients with advanced or metastatic non-small-cell lung cancer: a randomized, controlled phase III trial. J Clin Oncol 30 (29):3640-3647

17. He K, Cui B, Li G, Wang H, Jin K, Teng L (2012) The effect of anti-VEGF drugs (bevacizumab and aflibercept) on the survival of patients with metastatic colorectal cancer (mCRC). OncoTargets and therapy 5:59-65

18. Wang TF, Lockhart AC (2012) Aflibercept in the treatment of metastatic colorectal cancer. Clin Med Insights 6:19-30 
19. Van Cutsem E, Tabernero J, Lakomy R, Prenen H, Prausova J, Macarulla T, Ruff P, van Hazel GA, Moiseyenko V, Ferry D, McKendrick J, Polikoff J, Tellier A, Castan R, Allegra C (2012) Addition of aflibercept to fluorouracil, leucovorin, and irinotecan improves survival in a phase III randomized trial in patients with metastatic colorectal cancer previously treated with an oxaliplatin-based regimen. J Clin Oncol 30 (28):3499-3506

20. Thai HT, Veyrat-Follet C, Vivier N, Dubruc C, Sanderink G, Mentre F, Comets E (2011) A mechanism-based model for the population pharmacokinetics of free and bound aflibercept in healthy subjects. British J Clin Pharmacol 72 (3):402-414

21. Lavielle M (2008) MONOLIX (MOdèles NOn LInéaires à effets miXtes). Orsay, France: MONOLIX group.

22. Kuhn E, Lavielle M (2005) Maximum likelihood estimation in nonlinear mixed effects models. Comput Stat Data Anal 49 (4):1020-1038

23. Samson A, Lavielle M, Mentre F (2007) The SAEM algorithm for group comparison tests in longitudinal data analysis based on non-linear mixed-effects model. Stat Med 26 (27):4860-4875

24. Wald A (1943) Tests of statistical hypotheses concerning several parameters when the number of observations is large. Trans Amer Math Soc 54 (3):426-482

25. Brendel K, Comets E, Laffont C, Laveille C, Mentre F (2006) Metrics for external model evaluation with an application to the population pharmacokinetics of gliclazide. Pharm Res 23 (9):2036-2049

26. Comets E, Brendel K, Mentre F (2008) Computing normalised prediction distribution errors to evaluate nonlinear mixed-effect models: the npde add-on package for R. Comput Methods Programs Biomed 90 (2):154-166

27. Comets E, Brendel K, Mentré F (2010) Model evaluation in nonlinear mixed effect models, with applications to pharmacokinetics. J Soc Fr Stat 151:106-128

28. Savic RM, Karlsson MO (2009) Importance of shrinkage in empirical Bayes estimates for diagnostics: problems and solutions. AAPS J 11 (3):558-569

29. Mager DE, Jusko WJ (2001) General pharmacokinetic model for drugs exhibiting targetmediated drug disposition. J Pharmacokinet Pharmacodyn 28 (6):507-532

30. Mager DE (2006) Target-mediated drug disposition and dynamics. Biochem Pharmacol 72 (1):1-10

31. Mager DE, Krzyzanski W (2005) Quasi-equilibrium pharmacokinetic model for drugs exhibiting target-mediated drug disposition. Pharm Res 22 (10):1589-1596

32. Gibiansky L, Gibiansky E, Kakkar T, Ma P (2008) Approximations of the target-mediated drug disposition model and identifiability of model parameters. J Pharmacokinet Pharmacodyn 35 (5):573-591

33. Gibiansky L, Gibiansky E (2010) Target-Mediated Drug Disposition: New Derivation of the Michaelis-Menten Model, and Why It Is Often Sufficient for Description of Drugs with TMDD. PAGE 19, Abstr 1728 [www.page-meeting.org/?abstract=1728]

34. Kut C, Mac Gabhann F, Popel AS (2007) Where is VEGF in the body? A meta-analysis of VEGF distribution in cancer. British J Cancer 97 (7):978-985

35. Stefanini MO, Wu FT, Mac Gabhann F, Popel AS (2008) A compartment model of VEGF distribution in blood, healthy and diseased tissues. BMC Syst Biol 2:77

36. Lu JF, Bruno R, Eppler S, Novotny W, Lum B, Gaudreault J (2008) Clinical pharmacokinetics of bevacizumab in patients with solid tumors. Cancer Chemother Pharmacol 62 (5):779-786 
37. Fasanmade AA, Adedokun OJ, Ford J, Hernandez D, Johanns J, Hu C, Davis HM, Zhou H (2009) Population pharmacokinetic analysis of infliximab in patients with ulcerative colitis. Eur J Clin Pharmacol 65 (12):1211-1228

38. Kerbel R, Folkman J (2002) Clinical translation of angiogenesis inhibitors. Nat Rev Cancer 2 (10):727-739

39. Li J, Wientjes MG, Au JL (2010) Pancreatic cancer: pathobiology, treatment options, and drug delivery. AAPS J 12 (2):223-232

40. Kindler HL, Niedzwiecki D, Hollis D, Sutherland S, Schrag D, Hurwitz H, Innocenti F, Mulcahy MF, O'Reilly E, Wozniak TF, Picus J, Bhargava P, Mayer RJ, Schilsky RL, Goldberg RM (2010) Gemcitabine plus bevacizumab compared with gemcitabine plus placebo in patients with advanced pancreatic cancer: phase III trial of the Cancer and Leukemia Group B (CALGB 80303). J Clin Oncol 28 (22):3617-3622

41. Rudge JS, Holash J, Hylton D, Russell M, Jiang S, Leidich R, Papadopoulos N, Pyles EA, Torri A, Wiegand SJ, Thurston G, Stahl N, Yancopoulos GD (2007) VEGF Trap complex formation measures production rates of VEGF, providing a biomarker for predicting efficacious angiogenic blockade. Proc Nat Acad Sci USA 104 (47):18363-18370 


\section{Tables}

Table 1. Summary of clinical trials of aflibercept included in the analysis

\begin{tabular}{|c|c|c|c|c|c|}
\hline Study & $\begin{array}{l}\text { Aflibercept } \\
\text { dose }(\mathrm{mg} / \mathrm{kg})\end{array}$ & $\begin{array}{l}\text { Dosing } \\
\text { frequency }\end{array}$ & $\begin{array}{l}\text { Concomitant } \\
\text { chemotherapy }\end{array}$ & $\begin{array}{l}\text { Sampling scheme } \\
\text { frequency }\end{array}$ & $\begin{array}{l}\text { Number } \\
\text { of patients } \\
\text { with PK data }\end{array}$ \\
\hline \multicolumn{6}{|l|}{ Phase I } \\
\hline $\begin{array}{l}\text { TED6115/6116: dose- } \\
\text { escalation, solid tumors }\end{array}$ & $2,3,4,5,7$ & q2wk & single agent & $\begin{array}{l}\text { full profile }{ }^{a} \\
(\mathrm{n}=12-15)\end{array}$ & 37 \\
\hline $\begin{array}{l}\text { TCD6118: dose-escalation, } \\
\text { combination, solid tumors }\end{array}$ & $2,4,5,6$ & q2wk & $\begin{array}{l}\text { irinotecan/5-FU } \\
/ \mathrm{LV}\end{array}$ & $\begin{array}{l}\text { full profile }{ }^{b} \\
(\mathrm{n}=19)\end{array}$ & 61 \\
\hline $\begin{array}{l}\text { TCD6120: dose-escalation, } \\
\text { combination,solid tumors }\end{array}$ & $2,4,5,6,7,9$ & $\mathrm{q} 3 \mathrm{wk}$ & docetaxel & $\begin{array}{l}\text { full profile }{ }^{\mathrm{c}} \\
(\mathrm{n}=12)\end{array}$ & 53 \\
\hline \multicolumn{6}{|l|}{ Phase II } \\
\hline $\begin{array}{l}\text { ARD6122: dose- } \\
\text { escalation, ovarian cancer }\end{array}$ & 2,4 & $\mathrm{q} 2 \mathrm{wk}$ & single agent & $\begin{array}{l}\text { peak }(\text { Cycle } 1) \& \\
\text { multiple troughs }\end{array}$ & 175 \\
\hline ARD6123: NSCLC & 4 & q2wk & single agent & $\begin{array}{l}\text { peak (Cycle } 1) \& \\
\text { multiple troughs }\end{array}$ & 77 \\
\hline $\begin{array}{l}\text { EFC6125: ovarian cancer } \\
\text { with ascites }\end{array}$ & 4 & q2wk & single agent & $\begin{array}{l}\text { peak (Cycle } 1) \& \\
\text { multiple troughs }\end{array}$ & 30 \\
\hline \multicolumn{6}{|l|}{ Phase III } \\
\hline $\begin{array}{l}\text { VANILLA: combination, } \\
\text { pancreatic cancer }\end{array}$ & 4 & q2wk & gemcitabine & $\begin{array}{l}\text { peak }(\text { Cycle } 1) \& \\
\text { multiple troughs }\end{array}$ & 204 \\
\hline $\begin{array}{l}\text { VITAL: combination, } \\
\text { NSCLC }\end{array}$ & 6 & q3wk & docetaxel & $\begin{array}{l}\text { peak }(\text { Cycle } 1) \& \\
\text { multiple troughs }\end{array}$ & 370 \\
\hline $\begin{array}{l}\text { VELOUR: combination, } \\
\text { colorectal cancer }\end{array}$ & 4 & q2wk & FOLFIRI & $\begin{array}{l}\text { peak (Cycle } 1) \& \\
\text { multiple troughs }\end{array}$ & 500 \\
\hline
\end{tabular}

n: number of sampling times per patient, NSCLC: non small cell lung carcinoma, LV: leucovorin, 5-FU: 5-fluorouracil q2wk/q3wk: every two/three weeks, FOLFIRI: combination of irinotecan.5-FU/LV with different doses to that in TCD6118

${ }^{a}$ For study TED6115, samples were taken at pre-dose and at 1, 2, 4, 8, 24, 30, 48, 96, 168 hours post-dose of the first administration; pre-dose, post-dose and 7 days post-dose of the second administration. For study TED6116, an extension of TED6115, samples were taken prior to and at the end of each cycle in all cohorts and then at the end of the study and 3 months after the last dose.

${ }^{\mathrm{b}}$ This study was in 2 parts, part 1 open-label, multicenter, dose-escalation design and part 2 started double-blind, multicenter, randomized, parallel group, placebo controlled design. For part 1, samples were taken 5 minutes prior to dosing and at 1, 2, 4, 8, 24, 30, and 48 hours, and 7 days after dosing on Day 1 of Cycles 1 and 2. For all subsequent cycles, samples were collected 5 minutes prior to dosing, and at the end of aflibercept treatment. For part 2, samples were taken 5 minutes prior to dosing for all cycles, and at the end of aflibercept treatment, a final sample was collected.

${ }^{\mathrm{c}}$ During Cycle 1, samples were taken before administration of aflibercept, and at 1, 2, 4, 8, 24 (Day 2), and 48 hours (Day 3) and 7 (Day 8) and 14 (Day 15) days, after the start of aflibercept infusion. For all subsequent cycles, samples were collected only before the administration of aflibercept. 
Table 2. Characteristics of the patient study population at the entrance of the trial

\begin{tabular}{|c|c|c|c|}
\hline & $\begin{array}{l}\text { Number of } \\
\text { patients }(\%)\end{array}$ & Mean \pm SD & Median $(5-95 \%)$ \\
\hline \multicolumn{4}{|l|}{ Patient demographics } \\
\hline Age (years) & & $59.3 \pm 10.3$ & $60.0(41.0-75.0)$ \\
\hline Weight (kg) & & $71.8 \pm 16.1$ & $70.0(49.0-99.1)$ \\
\hline$<50 \mathrm{~kg}$ & $88(5.8)$ & & \\
\hline $50-100 \mathrm{~kg}$ & $1344(89.2)$ & & \\
\hline$>=100 \mathrm{~kg}$ & $74(4.9)$ & & \\
\hline \multicolumn{4}{|l|}{ Sex } \\
\hline Male & $767(50.9)$ & & \\
\hline Female & $739(49.1)$ & & \\
\hline \multicolumn{4}{|l|}{ Ethnicity } \\
\hline Caucasian & $1377(91.4)$ & & \\
\hline Black & $27(1.8)$ & & \\
\hline Asian & $75(5.0)$ & & \\
\hline Other & $27(1.8)$ & & \\
\hline \multicolumn{4}{|l|}{ Laboratory measurements } \\
\hline Albumin $(\mathrm{ALB})^{*}$ & & $0.79 \pm 0.22$ & $0.80(0.57-0.97)$ \\
\hline Alkaline phosphatase $(\mathrm{ALK})^{*}$ & & $1.18 \pm 0.94$ & $0.86(0.42-3.32)$ \\
\hline Alanine amino transferase (ALT)* & & $0.70 \pm 0.53$ & $0.55(0.22-1.65)$ \\
\hline Aspartate amino transferase (AST)* & & $0.88 \pm 0.62$ & $0.72(0.33-2.06)$ \\
\hline Bilirubin (BIL)* & & $0.51 \pm 0.26$ & $0.46(0.20-1.00)$ \\
\hline Total protein $(\mathrm{TP})^{*}$ & & $0.88 \pm 0.10$ & $0.88(0.74-1.03)$ \\
\hline Creatitine clearance (CLCR) (mL/min) & & $89.9 \pm 31.5$ & $84.2(47.9-148)$ \\
\hline \multicolumn{4}{|l|}{ Cancer type } \\
\hline Colorectal & $499(33.1)$ & & \\
\hline Non-small cell lung & $447(29.7)$ & & \\
\hline Pancreatic & $204(13.5)$ & & \\
\hline Ovarian & $205(13.6)$ & & \\
\hline Other solid tumors & $151(10.0)$ & & \\
\hline \multicolumn{4}{|l|}{ Cancer treatment } \\
\hline monotherapy & $319(21.2)$ & & \\
\hline combined chemotherapy & $1187(78.8)$ & & \\
\hline docetaxel & $423(28.1)$ & & \\
\hline irinotecan/5-FU /LV & $61(4.1)$ & & \\
\hline gemcitabine & $204(13.5)$ & & \\
\hline FOLFIRI & $499(33.1)$ & & \\
\hline \multicolumn{4}{|l|}{ Dose regimen } \\
\hline $4 \mathrm{mg} / \mathrm{kg}$ q2wk & $939(62.3)$ & & \\
\hline $6 \mathrm{mg} / \mathrm{kg} \mathrm{q} 3 \mathrm{wk}$ & $399(26.5)$ & & \\
\hline other multiple doses & $168(11.1)$ & & \\
\hline \multicolumn{4}{|l|}{ Pharmacokinetic sampling } \\
\hline Intensive & $151(10.0)$ & & \\
\hline Peak and trough & $1355(90.0)$ & & \\
\hline
\end{tabular}

*The measurements were normalized to the upper normal limit value of each laboratory 
Table 3. Parameter estimates of the base and final model

\begin{tabular}{|c|c|c|c|c|}
\hline \multirow[b]{2}{*}{ Parameter } & \multicolumn{2}{|c|}{ Base model } & \multicolumn{2}{|c|}{ Final model } \\
\hline & Estimate (RSE \%) & IIV (RSE\%) & Estimate (RSE \%) & IIV (RSE \%) \\
\hline$C L_{f}(\mathrm{~L} /$ day $)$ & $0.85(2)$ & $35.2(3)$ & $0.88(2)$ & $30.9(3)$ \\
\hline$\beta_{\text {CLf, female }}$ & - & - & $-0.15(16)$ & - \\
\hline$\beta_{\mathrm{CLf} \text {, weight }}$ & - & - & $0.33(19)$ & - \\
\hline$\beta_{\mathrm{CLf}, \mathrm{CLCR}}$ & - & - & $0.18(20)$ & - \\
\hline$\beta_{\mathrm{CLf}, \mathrm{ALB}}$ & - & - & $-0.39(14)$ & - \\
\hline$\beta_{\mathrm{CLf}, \mathrm{ALK}}$ & - & - & $0.10(18)$ & - \\
\hline$\beta_{\mathrm{CLf}, \mathrm{ALT}}$ & - & - & $-0.06(30)$ & - \\
\hline$\beta_{\mathrm{CLf}, \text { gemcitabine }}$ & - & - & $0.09(37)$ & - \\
\hline$V_{p}(\mathrm{~L})$ & $3.87(1)$ & $26.8(5)$ & $4.35(2)$ & $22.4(6)$ \\
\hline$\beta_{\mathrm{Vp}, \text { female }}$ & - & - & $-0.21(12)$ & - \\
\hline$\beta_{\mathrm{Vp}, \text { weight }}$ & - & - & $0.39(16)$ & - \\
\hline$\beta_{\mathrm{Vp}, \mathrm{CLCR}}$ & - & - & $0.10(39)$ & - \\
\hline$Q$ (L/day) & $1.68(8)$ & $81.9(9)$ & $1.49(9)$ & $85.5(9)$ \\
\hline$V_{t}(\mathrm{~L})$ & $3.75(5)$ & $64.2(4)$ & $3.72(5)$ & $65.8(4)$ \\
\hline$V_{b}(\mathrm{~L})$ & $3.92(10)$ & $29.1(5)$ & $4.14(10)$ & $27.5(6)$ \\
\hline$V_{\max }(\mathrm{mg} / \mathrm{day})$ & $0.77(10)$ & - & $0.82(10)$ & - \\
\hline$K_{m}(\mu \mathrm{g} / \mathrm{mL})$ & $1.79(7)$ & $41.2(22)$ & $1.92(9)$ & $28.2(42)$ \\
\hline$\beta_{\mathrm{Km}, \text { female }}$ & - & - & $-0.23(35)$ & - \\
\hline$\beta_{\mathrm{Km}, \mathrm{ALT}}$ & - & - & $0.26(46)$ & - \\
\hline$\beta_{\mathrm{Km}, \mathrm{AST}}$ & - & - & $-0.26(37)$ & - \\
\hline$\beta_{\mathrm{Km} \text {, gemcitabine }}$ & - & - & $0.60(17)$ & - \\
\hline$C L_{b}$ (L/day) & $0.18(10)$ & $23.5(3)$ & $0.19(10)$ & $22.3(3)$ \\
\hline$\beta_{\mathrm{CLb} \text {,age }}$ & - & - & $0.18(26)$ & - \\
\hline$\beta_{\mathrm{CLb}, \mathrm{CLCR}}$ & - & - & $0.09(31)$ & - \\
\hline$\beta_{\mathrm{CLf}, \mathrm{ALB}}$ & - & - & $-0.13(33)$ & - \\
\hline$\beta_{\mathrm{CLf}, \mathrm{ALT}}$ & - & - & $-0.08(27)$ & - \\
\hline$\beta_{\mathrm{CLf} \text {, irinotecan/5-FU/LV }}$ & - & - & $-0.13(26)$ & - \\
\hline$\beta_{\mathrm{CLf} \text {, docetaxel }}$ & - & - & $0.06(30)$ & - \\
\hline$\sigma_{f a}(\mu \mathrm{g} / \mathrm{mL})$ & $0.04(6)$ & - & $0.04(6)$ & - \\
\hline$\sigma_{f p}(\%)$ & $32.90(1)$ & - & $32.80(1)$ & - \\
\hline$\sigma_{b a}(\mu \mathrm{g} . \mathrm{eq} / \mathrm{mL})$ & $0.34(2)$ & - & $0.34(2)$ & - \\
\hline$\sigma_{b p}(\%)$ & $9.01(4)$ & - & $9.04(4)$ & - \\
\hline
\end{tabular}


Table 4. Assessment of covariate effects on aflibercept pharmacokinetic parameters

\begin{tabular}{|c|c|c|c|c|c|c|c|c|c|}
\hline Covariate & Quantiles & $\begin{array}{c}\mathbf{C} \mathbf{L}_{\mathrm{f}} \\
\text { (L/day) }\end{array}$ & $\begin{array}{c}\% \\
\text { Change }^{\dagger} \\
\end{array}$ & $\begin{array}{l}\mathbf{V}_{\mathbf{p}} \\
(\mathbf{L})\end{array}$ & $\begin{array}{c}\% \\
\text { Change }^{\dagger} \\
\end{array}$ & $\underset{(\mu \mathrm{g} / \mathbf{m L})}{\mathbf{K}_{\mathrm{m}}}$ & $\begin{array}{c}\% \\
\text { Change }^{\dagger} \\
\end{array}$ & $\begin{array}{c}\mathbf{C L}_{\mathbf{b}} \\
(\mathbf{L} / \mathbf{d a y})\end{array}$ & $\begin{array}{c}\% \\
\text { Change }^{\dagger} \\
\end{array}$ \\
\hline $\begin{array}{l}\text { Typical } \\
\text { patient }^{*}\end{array}$ & & 0.88 & & 4.35 & & 1.92 & & 0.19 & \\
\hline Sex & Female & 0.76 & -14.1 & 3.53 & -18.9 & 1.53 & -20.2 & - & \\
\hline WT & $\begin{array}{l}5 \%: 49 \\
95 \%: 99.1\end{array}$ & $\begin{array}{l}0.79 \\
1.00\end{array}$ & $\begin{array}{l}-11.0 \\
12.0\end{array}$ & $\begin{array}{l}3.78 \\
4.99\end{array}$ & $\begin{array}{l}-13.1 \\
14.6\end{array}$ & - & & - & \\
\hline Age & $\begin{array}{l}5 \%: 41 \\
95 \%: 75\end{array}$ & - & & - & & - & & $\begin{array}{l}0.18 \\
0.20\end{array}$ & $\begin{array}{l}-6.6 \\
4.1 \\
\end{array}$ \\
\hline CLCR & $\begin{array}{l}5 \%: 47.9 \\
95 \%: 148.1\end{array}$ & $\begin{array}{l}0.80 \\
0.98\end{array}$ & $\begin{array}{l}-9.3 \\
11.2\end{array}$ & $\begin{array}{l}4.13 \\
4.60\end{array}$ & $\begin{array}{l}-5.1 \\
5.9\end{array}$ & - & & $\begin{array}{l}0.18 \\
0.20\end{array}$ & $\begin{array}{c}-4.6 \\
5.2\end{array}$ \\
\hline ALB & $\begin{array}{l}5 \%: 0.57 \\
95 \%: 0.965\end{array}$ & $\begin{array}{l}1.00 \\
0.82\end{array}$ & $\begin{array}{l}14.1 \\
-7.0\end{array}$ & - & & - & & $\begin{array}{l}0.20 \\
0.19\end{array}$ & $\begin{array}{r}4.6 \\
-2.5\end{array}$ \\
\hline ALK & $\begin{array}{l}5 \%: 0.423 \\
95 \%: 3.233\end{array}$ & $\begin{array}{l}0.82 \\
1.01 \\
\end{array}$ & $\begin{array}{l}-7.0 \\
14.4 \\
\end{array}$ & - & & - & & - & \\
\hline ALT & $\begin{array}{l}5 \%: 0.222 \\
95 \%: 1.646\end{array}$ & $\begin{array}{l}0.93 \\
0.82 \\
\end{array}$ & \begin{tabular}{|l|}
5.8 \\
-6.6 \\
\end{tabular} & - & & $\begin{array}{l}1.52 \\
2.54 \\
\end{array}$ & $\begin{array}{l}-20.6 \\
32.5 \\
\end{array}$ & $\begin{array}{l}0.20 \\
0.17 \\
\end{array}$ & $\begin{array}{r}7.6 \\
-8.5 \\
\end{array}$ \\
\hline AST & $\begin{array}{l}5 \%: 0.333 \\
95 \%: 2.058\end{array}$ & - & & - & & $\begin{array}{l}2.35 \\
1.46\end{array}$ & $\begin{array}{c}22.3 \\
-24.0\end{array}$ & - & \\
\hline Combination & $\begin{array}{l}\text { gemcitabine } \\
\text { irinotecan/ } \\
5 \text {-FU/LV } \\
\text { docetaxel }\end{array}$ & 0.96 & 9.2 & - & & 3.49 & 82.0 & $\begin{array}{c}- \\
0.17 \\
0.20 \\
\end{array}$ & $\begin{array}{l}-12.5 \\
6.5 \\
\end{array}$ \\
\hline
\end{tabular}

*: male, 60 years, $70 \mathrm{~kg}$, normalized ALB of 0.80, normalized ALK of 0.86, normalized ALT of 0.55, normalized AST of 0.72 , CLCR of $82.2 \mathrm{~mL} / \mathrm{min}$, receiving aflibercept as a monotherapy

$t:$ theoretical effect (\% change with respect to the typical value) of the covariate considered alone, the other covariate being set to its median value

$\%$ changes in PK parameters greater than $20 \%$ are presented in bold 


\section{Figure legends}

Figure 1

Proposed structural model for free and bound aflibercept. Free aflibercept in plasma distributes first to tissues then binds to VEGF to form a complex. Binding to VEGF occurs in the peripheral compartment, follows the law of mass action and can be characterised by a nonlinear equation with MM constants $\left(V_{\max }, K_{m}\right)$. Bound aflibercept (complex) is assumed to be directly eliminated through internalisation $\left(k_{\text {int }}\right)$.

Figure 2

Goodness-of-fit plots: (top) observed versus predicted concentrations for free aflibercept; (bottom) observed versus predicted concentrations for bound aflibercept. The plots on the left present observed versus the population predicted concentration (PRED) while the plots on the right present observed versus individual predicted concentrations (IPRED). One outlier was removed from the plots.

Figure 3

Normalised prediction distribution error (NPDE) vs time since last dose (TimeL) for free aflibercept (top) and bound aflibercept (bottom) with 95\% prediction intervals around the the $10^{\text {th }}, 50^{\text {th }}, 90^{\text {th }}$ percentiles. NPDE plots for TimeL $\leq 22$ weeks are presented in the left and for TimeL $\leq 6$ weeks in the right. Observed data are plotted using a circle $\left({ }^{\circ}\right)$. The solid line represents the $10^{\text {th }}, 50^{\text {th }}$ and $90^{\text {th }}$ percentiles of the npde corresponding to observed data. The shaded area represents $95 \%$ prediction intervals for the selected percentiles (pink for $50^{\text {th }}$ percentiles and blue for others).

Figure 4

Examples of individual fits of free and bound aflibercept for 4 subjects in different studies. From left to right: study TED6115 (phase I), study ARD6123 (phase II), study Vital (phase III), and study VELOUR (phase III). Fits for free aflibercept are presented in the top, bound afibercept in the bottom. Observed data are plotted using a circle $\left({ }^{\circ}\right)$. The line $(-)$ represents the prediction of model. 
Figure 5

Predicted median profiles of bound aflibercept at steady-state with different dosing regimens (2, 4, $6 \mathrm{mg} / \mathrm{kg}$ q2wk or q3wk) illustrated by vertical lines to $\mathrm{x}$-axis (blue for q2wk and grey for q3wk dosing regimen).

Figure 6

Predicted steady-state concentrations of free aflibercept (left y-axis) and bound aflibercept (right $\mathrm{y}$-axis) following 8 aflibercept doses of $4 \mathrm{mg} / \mathrm{kg}$ q2wk during 24 weeks. 


\section{Figures}

Figure 1.

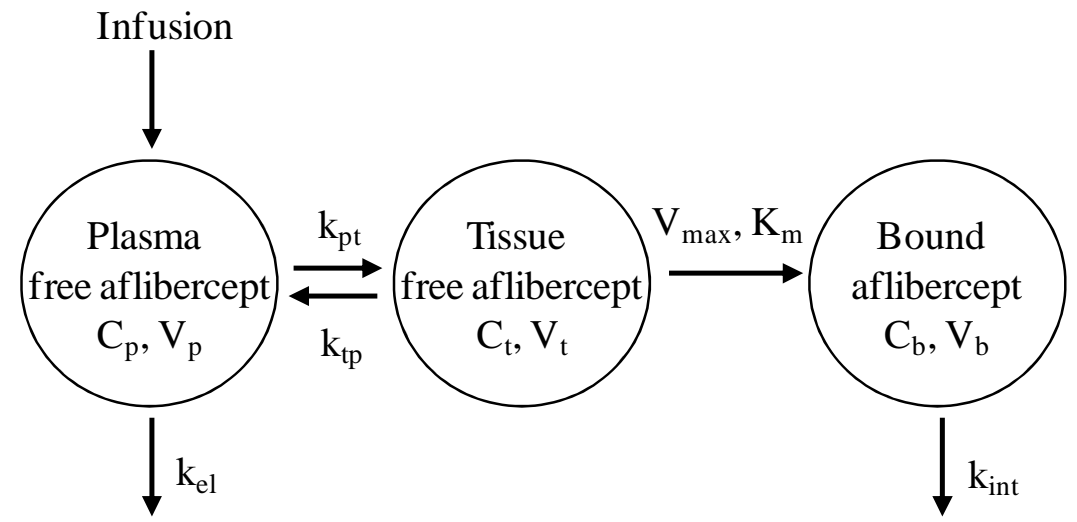


Figure 2.

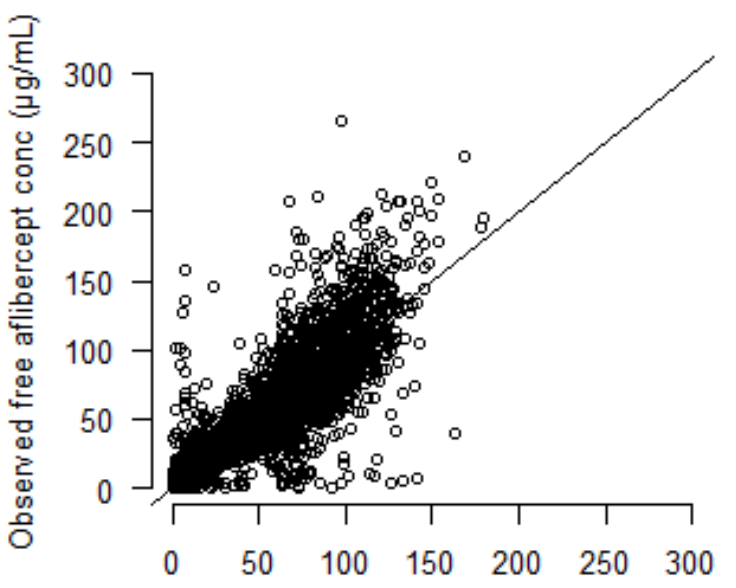

PRED for free aflibercept $(\mu \mathrm{g} / \mathrm{mL})$

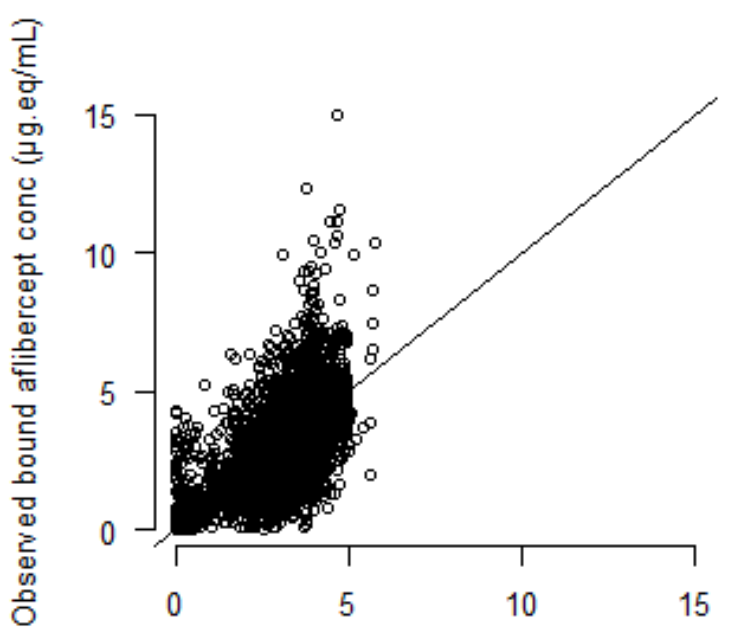

PRED for bound aflibercept ( $\mu \mathrm{g} . \mathrm{eq} / \mathrm{mL}$ )

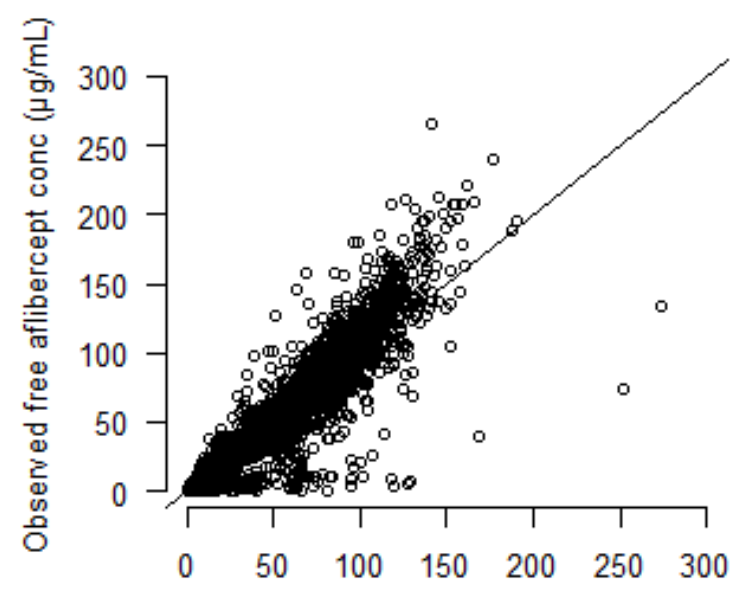

IPRED for free aflibercept $(\mu \mathrm{g} / \mathrm{mL})$

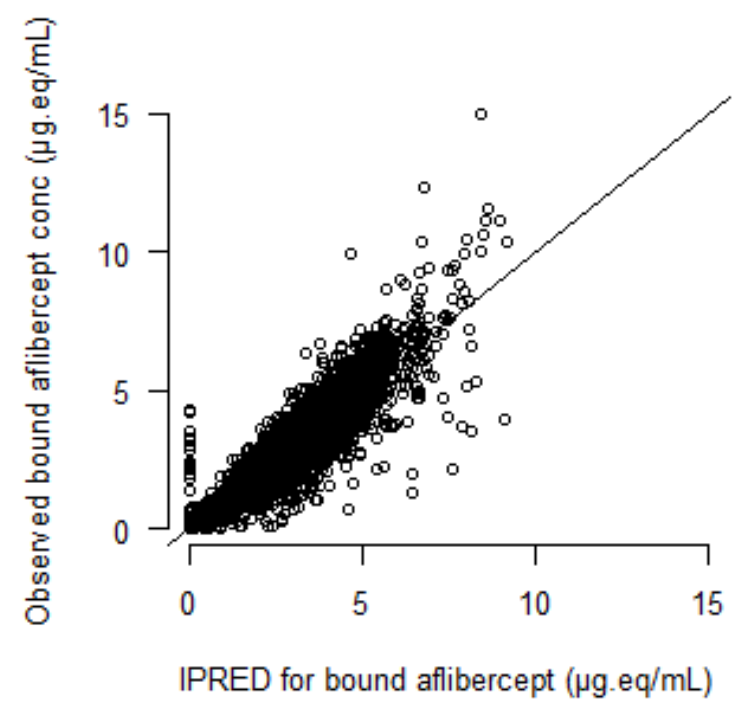


Figure 3.
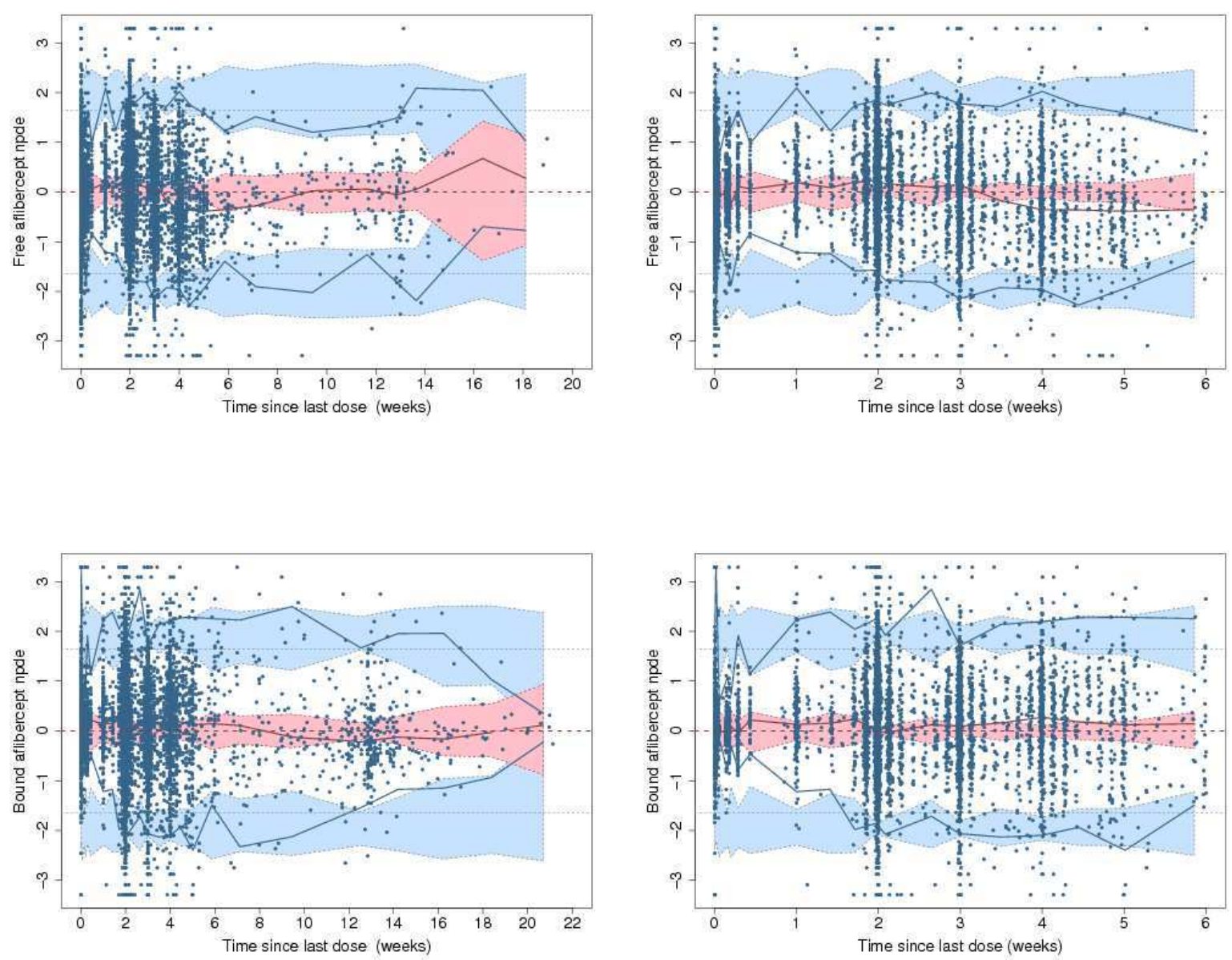
Figure 4.
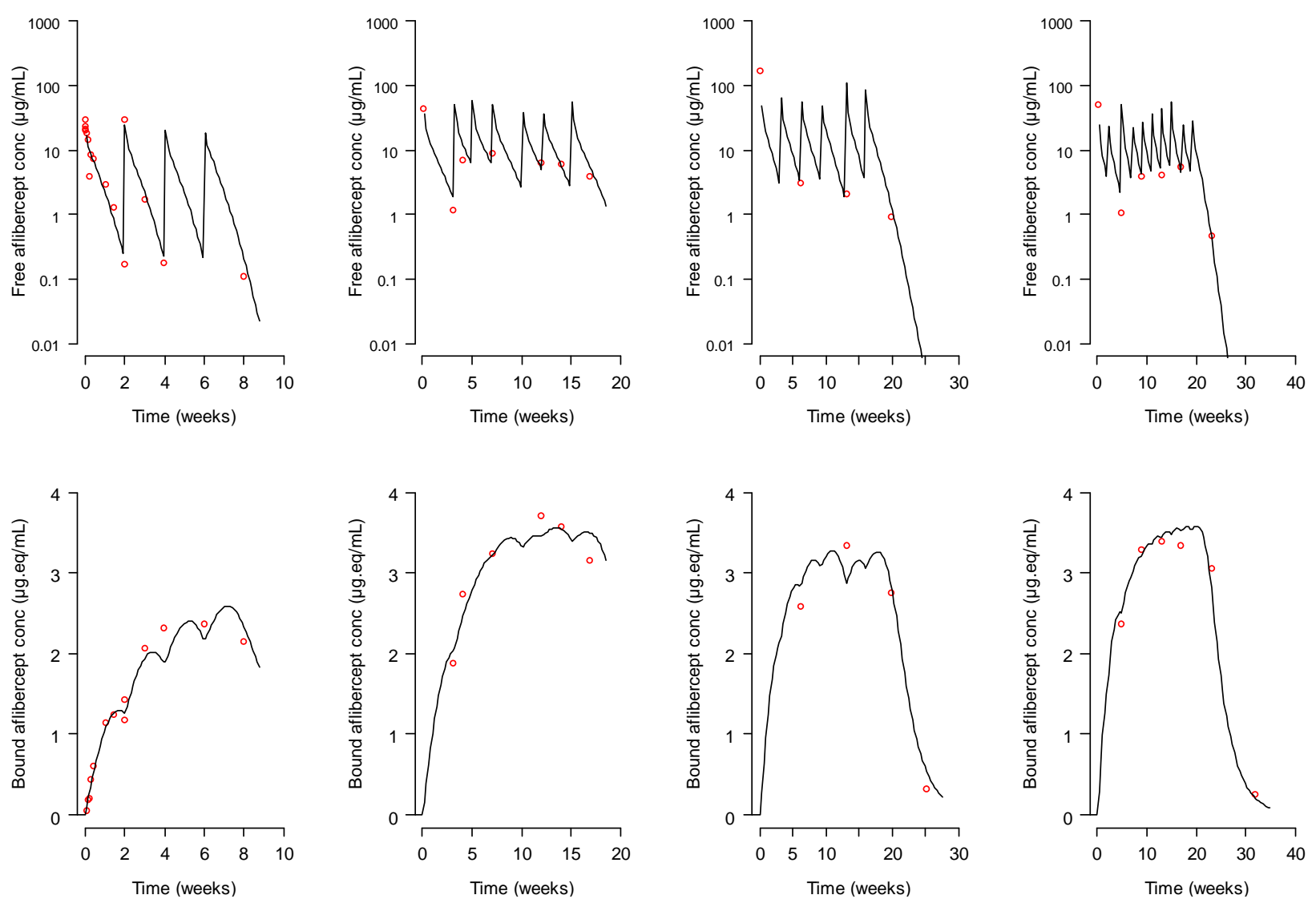
Figure 5.

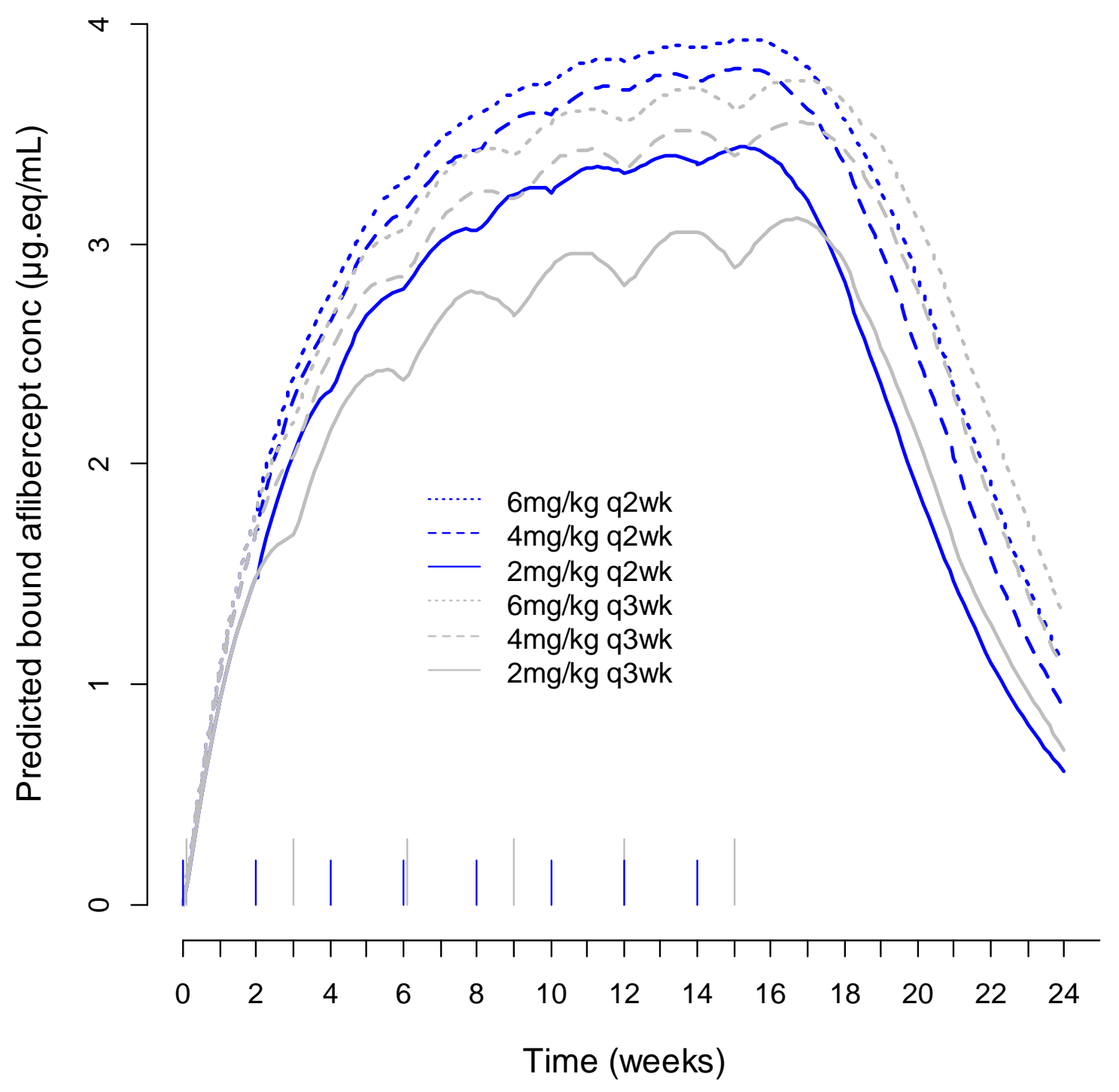


Figure 6.

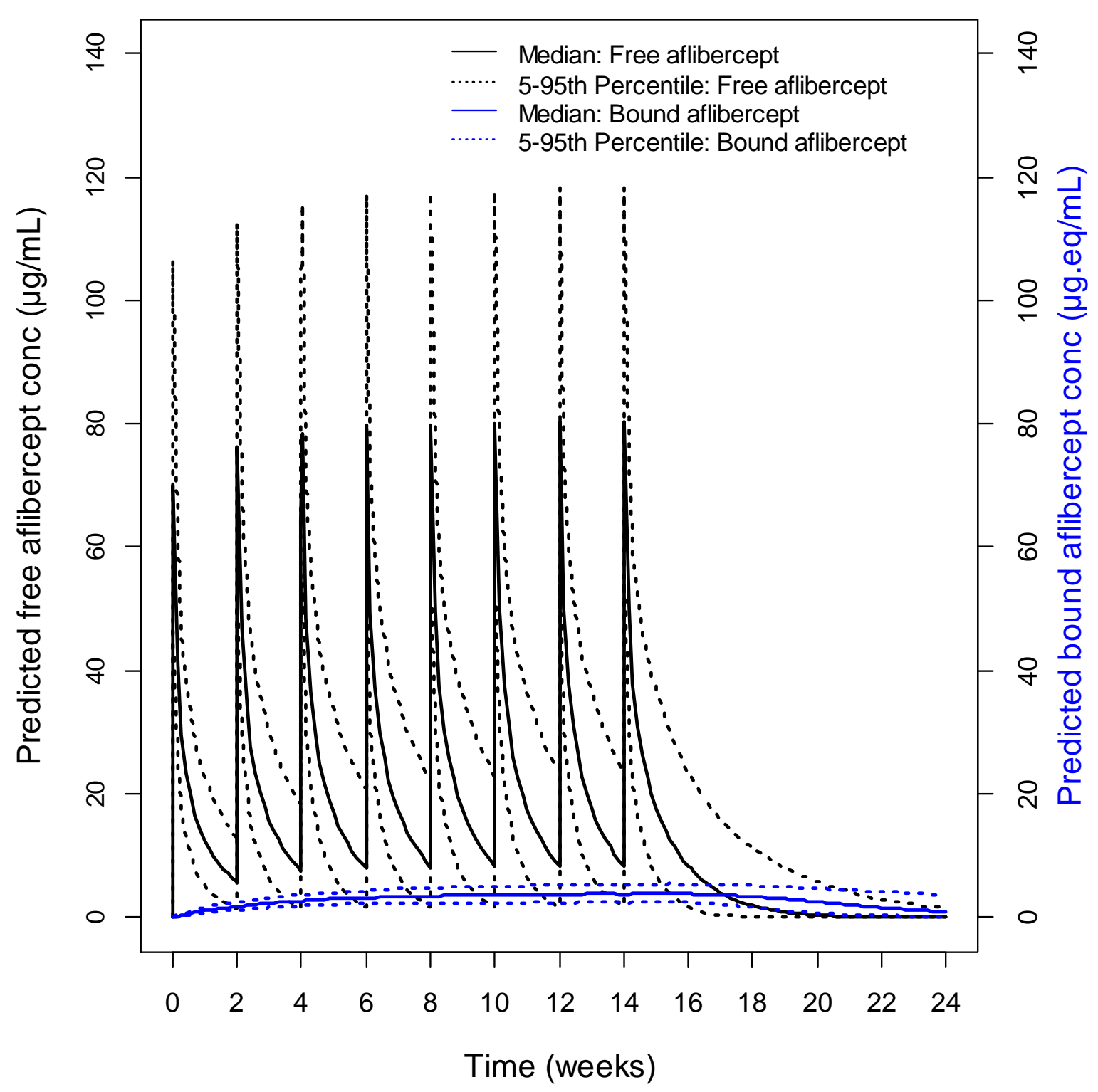

